\title{
The Compliance Analysis on Transaction Risk of Electricity Market Based on the Release of Retail Side
}

\author{
Tianqi Tang ${ }^{1, a}$, Jianhua Yang ${ }^{2, b}$ \\ ${ }^{1}$ North China Electric Power University, Beijing 102206,P.R.China \\ ${ }^{2}$ Central China Grid Company Limited, Wuhan, China \\ azhaojw923@163.com,2227262318@qq.com
}

\begin{abstract}
Keywords: compliance risk management; electricity market; electricity transaction; plant and grid order.

Abstract. With the new development of electricity reform, many problems that involving the release of retail side need to be solved, which makes the compliance risk management very crucial. Compliance risk management is a kind of management theory that can proactively identify and manage the compliance risks that may exist, and propose preventive measures based on the compliance program, this theory can improve the market mechanism effectively. This paper analyzed the problems of compliance risk management in electricity market from three aspects, and proposed some solutions to enhance the management.
\end{abstract}

\section{Introduction}

China's power generation segment has established a competitive market, so pushing the release of retail side by constructing multiple retail subject, giving purchase options to end-users, bringing competition into the retail side, finally forming a new market structure has become the consensus of electricity reform.

The release of retail side involves the reconstruction of electricity sale market, it is a systematic project that has a wide range and a huge workload, it will also influence multiple retail subjects, so there are a number of key issues need to be solved. These issues relate to many major reform, including market construction, industry regulation, trading mechanism, price mechanism, laws and regulations and business. The paper will analyze the relevant risks after the release based on compliance management, to promote sale market playing a role in optimal allocation of energy resources.

\section{Compliance risk management}

Compliance means making a company's business activities consistent with applicable laws, regulations, rules, relevant standards, ethics and morality. Compliance management refers to the security company formulating and implementing the compliance management system, establishing compliance management mechanism, fostering compliance culture, preventing compliance risk behavior, it is a internal core risk management of company. In the power industry, compliance management is the establishment of compliance management mechanism, with this mechanism company can proactively identify and manage the compliance risks that may exist, and propose preventive measures based on the compliance program.

Compliance risk refers to the legal sanctions and the losses that bank may suffer for failing to follow the relevant laws, regulations and guidelines. In the electricity market, compliance risk means the legal or regulatory sanctions, penalties and significant financial losses that company may suffer for failing to comply with compliance laws, rules and guidelines.

The highest level of compliance risk management is the establishment of compliance culture. Power companies should advocate and cultivate their own compliance culture, and see it as an important part of the corporate culture. The purpose is to promote the culture construction of power company, and to encourage all employees to comply with the relevant laws, rules, standards and social morality when involved in the electricity business. 


\section{Compliance risk management in electricity market}

\subsection{Operation and order regulation of electricity market}

(1) The joint meeting with plant and grid company. Through the joint meeting platform, Power plants and grid company can have equal consultation and democratic decisions, they can issue relevant information, discuss the development of power industry, negotiate problems existing in the production and operation of power industry, to promote the healthy and rapid development of power industry.

(2) Information disclosure and submission of company. Power enterprises and dispatching trading institutions by disclosing information about power construction, production, management, price and service, to strengthen supervision and maintain the order of electricity market.

(3) Contract agreement for the record. The relevant contracts and agreements signed by power market participants need to be filed as required.

(4) Interviews. Regulators conduct interviews to provincial power grid and different types of power generation companies, in-depth understanding the situation of electricity trading and market order, realizing the business demands and suggestions about regulatory work, putting up solutions for related problems, to promote standardized operation of electricity market.

(5) Generating units enter and exit the business operation. Power generation enterprises should apply test operation to grid company according to relevant rules in advance, company should arrange the commissioning based on the actual situation, to promote the safe and stable operation of power grid and the grid generation unit.

(6) Establishment of monitoring and evaluation system for the development and utilization of renewable energy. The provincial energy authorities should establish and improve the regional renewable energy development and utilization monitoring system, and in conjunction with the statistics department monitoring indicators annually, including the utilization amount of renewable energy, the proportion of renewable energy accounts for total energy consumption, the electricity share of non-hydroelectric renewable energy, regularly reported to the National Energy Board. Each electricity trading agency, grid company, power generation company shall submit relevant data to the national renewable energy information management system monthly.

\subsection{Power cost and electricity price of power grid}

(1) The regulation of transmission and distribution cost. Power grid companies should establish a sound accounting system for transmission and distribution cost, and it should be accounted separated from other business costs.

(2) Basic rules of electricity market operation. Regulating the electricity market contract transaction, spot transaction and futures transaction based on "Electricity Regulatory Ordinance" and other relevant laws, administrative regulations, in order to safeguard the legitimate interests of electricity market participants and guarantee power market unified, open, competitive and orderly.

2.3 Information submission of electricity companies

The submitted information including monthly financial report, annual financial accounting report and electricity billing information, so as to establish a continuing operation (financial) monitoring and early warning mechanism to monitor the business situation of power companies timely. 


\section{Problems of compliance risk management}

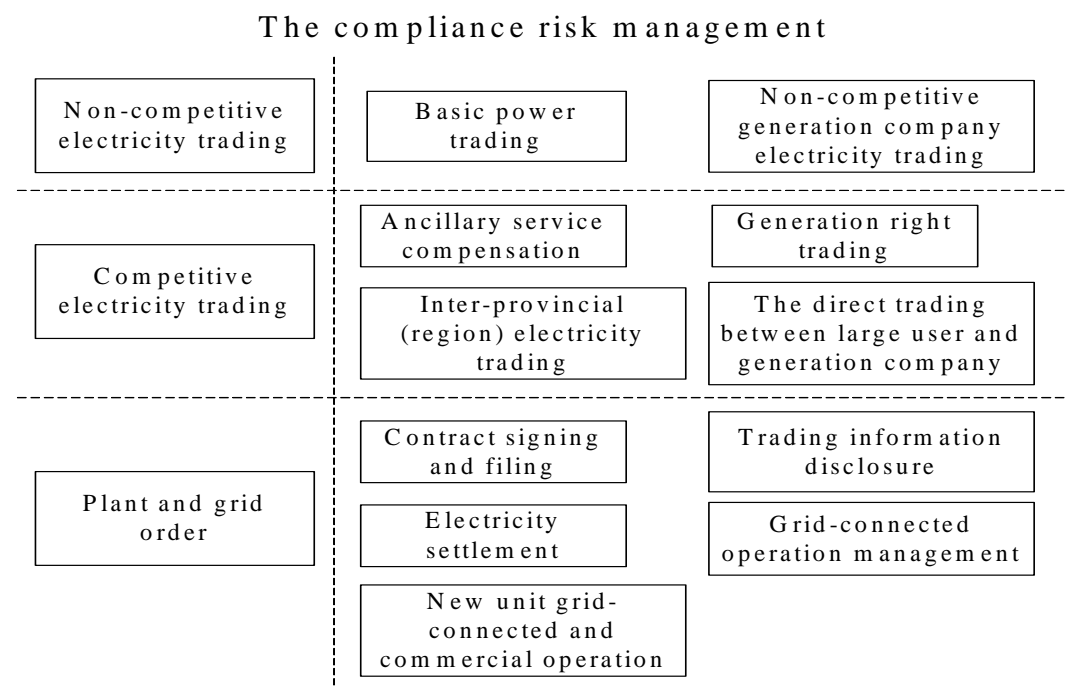

3.1 Non competitive electricity transaction. In base power trading, grid companies will conduct the base power plan unauthorized. For example, the company act as government to develop base power plan completely on their own. In power trading of non competitive power generation enterprises, some grid companies haven't performed a full acquisition for renewable energy electricity, there is a separate treatment for excess contract electricity.

3.2 Competitive electricity transaction. In inter-provincial (regions) power trading, due to the trading plan of power grid companies lack of scientific, there will be a deviation between the plan and the actual trading volume, some companies even not perform the trading plan. In generation right trading, the power loss compensation charge exist irregularities. For example, grid companies secretly collecting power loss compensation when the standard has not been delegated; charging power loss compensation without the approval of SERC. There are still problems in information disclosure. For example, not release the generation right transaction information on time, or the information is not complete. Local governments may force the direct trading between large power users and power companies. Trading organizations in some grid companies are not standardized, they using their own advantages to intervene the contract content signed by two sides. Auxiliary service compensation is not standard.

3.3 Plant and grid order. In terms of the contract and filing, some grid companies and generation companies do not sign the contract in the transaction, or not sign a new contract in time. In terms of transaction information disclosure, the power market transaction information disclosure is not timely and not comprehensive, In terms of electricity billing, some grid companies haven't paid full money to generation companies and formed debt. In grid operation, some power companies did not obtain power business license, and not re submit from the SERC timely. About the new unit into the commercial operation, some grid companies are not in accordance with provisions, extending the commissioning period of new machine unauthorizedly, disguised reduce commissioning price.

\section{The promotion of compliance risk management}

In the non-competitive electricity trading, the grid companies should be strictly in accordance with the base power plan that issued by government, and not be ultra vires. For renewable electricity acquisitions, it is necessary to strengthen job responsibilities and the awareness of "renewable energy full acquisition", and in accordance with national requirements for generation dispatching plan, to avoid renewable energy power generation can not have full access due to equipment problems, and make the settlement of electricity tariffs and subsidies timely and full.

In the competitive electricity trading, about inter-provincial transaction plan and actual transaction volume problem, grid companies should make the trading plan scientifically based on the last year's data and national economic development trend, to minimize deviations with actual volume. In 
organizational trading, the transaction should be based on the principle of voluntarism, not specify the price, the volume and the plant, grid companies should strictly implement the beforehand bidding, prior disclosure and advance pricing to ensure the trading open, fair and impartial. The grid companies should publish the following information timely and fully: generation right transaction confirmation, generation right transaction energy-saving emission reduction effect, power grid security check, electricity billing, loss compensation, the implementation of deviation. Local governments should follow the regulations to organize the transaction between large users and power generation companies, and the purchasing contract should be signed with the principle of self negotiation, any third party shall not interfere. In plant and grid order, the relevant departments should strengthen the supervision on tariff settlement, forming a virtuous circle and establishing relevant ledger. Regulatory should urge the grid companies that haven't got electric power business license to get license within the time limit, for the dispatching institution who did not apply for a license in time, their power shall be cease to use and they should suffer punishment. Grid companies shouldn't set up or improve business operating conditions without authorization, shouldn't disguise to extend the new unit commissioning period or lower their feed-in tariff, the regulations has been issued should be abolished and the grid need to return the illegal income to power generation companies.

\section{Conclusion}

Through the study on compliance risk management and the risk after the release of retail side, three main forms of compliance risk management in electricity market were put forward, that isnon-competitive electricity trading, competitive electricity trading and plant and grid order, and from these three aspects, the current status and problems of compliance risk management were analyzed, the solutions were proposed too, in order to facilitate the rationalization of power market and improve the efficiency of market transactions.

\section{References}

[1] Paulun T, Feess E, Madlener R. Why Higher Price Sensitivity of Consumers May Increase Average Prices: An Analysis of the European Electricity Market[J]. Ssrn Electronic Journal, 2010.

[2] Yu J, Zhou J Z, Yang J, et al. Agent-based retail electricity market: modeling and analysis[C]// International Conference on Machine Learning and Cybernetics. IEEE, 2004:95-100 vol.1.

[3] Wolak F A. An Empirical Analysis of the Impact of Hedge Contracts on Bidding Behavior in a Competitive Electricity Market[J]. International Economic Journal, 2000, 14(2):1-39.

[4] G. Henkelman, G.Johannesson and H. Jónsson, in: Theoretical Methods in Condencsed Phase Chemistry, edited by S.D. Schwartz, volume 5 of Progress in Theoretical Chemistry and Physics, chapter, 10, Kluwer Academic Publishers (2000).

[5] Wolak F, Patrick R H. The Impact of Market Rules and Market Structure on the Price Determination Process in the England and Wales Electricity Market[J]. Nber Working Papers, 1999.

[6] Tanskanen A, Jantunen A, Saksa J M, et al. Governance structures of the electricity distribution network operation activities: Towards a benefits-based analysis[J]. International Journal of Energy Sector Management, 2007, 1(4):307-321. 